\title{
Danos à saúde humana e ao meio ambiente ocasionados pelo uso de agrotóxicos na produção de produtos agrícolas no Brasil
}

\begin{abstract}
Neste estudo buscou estabelecer uma discussão sobre os principais condicionantes que podem impactar negativamente a saúde humana e o meio ambiente, quando se utiliza de forma indiscriminada agrotóxicos no tratamento de lavouras para a produção de produtos agrícolas no Brasil. A pesquisa foi desenvolvida por meio de uma revisão bibliográfica durante o período de 2009 a 2019, aliada a técnicas de análise descritivas e exploratória. Foi realizado consultas por artigos científicos nas bases de dados LILACS e ScienceDirect, através do cruzamento das palavras-chaves: agrotóxicos (agrotoxics), saúde humana (human health) e contaminação ambiental (environmental contamination), utilizando o operador lógico booleano "AND". Os artigos foram selecionados utilizando critérios de inclusão e exclusão, onde foram apreciados artigos publicados em periódicos nacionais e internacionais avaliados por pares, redigidos no idioma inglês e português, porém, não foram apreciados achados que utilizava método científico somente de revisão bibliográfica. Também foram considerados nesta pesquisa as publicações oficiais divulgadas pela Agência Nacional de Vigilância Sanitária - ANVISA, como o Programa de Análise de Resíduos de Agrotóxicos em Alimentos - PARA. Os resultados demonstraram que a pulverização aérea e a biotecnologia foram um dos principais condicionantes que promoveram o aumento do uso de substâncias químicas no agronegócio brasileiro, através da utilização de sementes transgênicas, que além de proporcionar uma maior produção, é resistente ao herbicida 2,4-D. Esse processo de produção quimicamente dependente tem contribuído para contaminação ambiental e se tornado um grave problema de saúde pública no Brasil, devido ao estado crítico de poluição do solo, água, biota, e, sobretudo, de casos de intoxicação alimentar e da exposição humana intensa a substâncias químicas.
\end{abstract}

Palavras-chave: Agrotóxicos; Saúde humana; Degradação ambiental

\section{Environmental and human health damage occasioned by the use of pesticides in the production of agricultural products in Brazil}

\begin{abstract}
In this study sought establish a discussion over the principals conditioning what they can impacts negatively the human health and the environment, when if utilize of form indiscriminate agrotoxics in the treatment of crops for the production of agricultural products in the Brazil. The research he was developed through of literature review during the period of 2009 the 2019, allied the techniques of descriptive and exploratory analysis. Was realized consultations by scientific articles in the data base LILACS and ScienceDirect, through of crossing of keywords: agrotoxics, human health and environmental contamination, utilizing the boolean logical operator "AND". The articles were selected utilizing inclusion and exclusion criteria, where were appreciated articles published in periodic nationals and internationals peer reviewed, written in english and portuguese, however, no were appreciated findings what utilize scientific method only bibliographic review. Also were considered in this research the official publications through the Brazilian Health Regulatory Agency - ANVISA, how the Programs for Pesticide Residues in Food - PARA. The results demonstrated what the aerial spraying and the biotechnology were a of principal conditioning what promoted the increase of use chemical substances of the agribusiness Brazilian, through gives utilization of transgenic seeds, what beyond of proportion a larger production, is resistant to the herbicide 2,4-D. That process of chemically production dependent has contributed for environmental contamination and if tornado a serious problem of public health in Brazil, owing to the critical condition of pollution from soil, water, biota, and, mainly, of cases of food intoxication and gives human exposure intense the chemical substances.
\end{abstract}

Keywords: Agrotoxics; Human health; Environmental Degradation.

Thays Lorranny da Silva Januário (iD) Universidade Regional do Cariri, Brasil http://lattes.cnpq.br/1451698935293740 http://orcid.org/0000-0002-0682-7629 eng.thays@hotmail.com

\section{Esdras Alex Freire de Oliveira}

Universidade Regional do Cariri, Brasil http://lattes.cnpq.br/4693470747465264 esdras-alex@hotmail.com

Thaygga Lorranny da Silva Januário Yamamoto (iD Universidade Estácio de Sá, Brasil http://lattes.cnpq.br/9708847257085767 http://orcid.org/0000-0003-1522-3381

thaygga@gmail.com
José Gonçalves de Araújo Filho Universidade Regional do Cariri, Brasil http://lattes.cnpq.br/4909589002760742 araujo.filho@urca.br

\section{Isadora Jeremias Sampaio}

Universidade Regional do Cariri, Brasil

http://lattes.cnpq.br/1446585744692315 isadora jeremias@hotmail.com

Allan freires de Oliveira

Universidade Federal do Cariri, Brasil

http://lattes.cnpq.br/2709596241787018

allanmajo@hotmail.com
Erlan Freires de Oliveira

Instituto Federal do Ceará, Brasil

http://lattes.cnpq.br/3916444946746814

erlanmajo@gmail.com
Referencing this:

JANUÁRIO, T. L. S.; OLIVEIRA, E. A. F.; YAMAMOTO, T. L. S. J.; ARAÚJO FILHO, J. G.; SAMPAIO, I. J.; OLIVEIRA, A. F.; OLIVEIRA, E. F.. Danos à saúde humana e ao meio ambiente ocasionados pelo uso de agrotóxicos na produção de produtos agrícolas no Brasil. Revista lbero Americana de Ciências Ambientais, v.12, n.5, p.462-477, 2021. DOI: http://doi.org/10.6008/CBPC2179-6858.2021.005.0037 


\section{INTRODUÇÃO}

Embora a agricultura seja praticada pela humanidade há mais de dez mil anos, o uso intensivo de agrotóxicos para o controle de pragas e doenças das lavouras existe há pouco mais de meio século (SHINOHARA et al., 2017). Entretanto, as modernas formas de cultivos agrícolas que faz uso intensivo de agrotóxicos ocasionam vastos problemas de saúde pública e ambiental, como a poluição dos recursos naturais e a intoxicação de trabalhadores rurais e da sociedade em geral (CORCINO et al., 2019).

No Brasil, a utilização intensiva de agrotóxicos nas lavouras agrícolas teve seu início a partir da década de 1960 com a chamada "revolução verde", objetivando modernizar a agricultura no país e elevar os níveis de produtividade desse setor, através de incentivos ficais e de financiamento. Durante essa época ocorreu o sancionamento da Lei do Crédito Rural em 1965 (Lei 4.829/65), que constitui um sistema nacional de crédito que vincula ao produtor rural à obrigatoriedade de adquirir e aplicar agrotóxicos e fertilizantes nas suas plantações, sendo que essa cultura de incentivo ao uso abusivo de produtos químicos na agricultura ganhou ainda mais impulso na década de 1970 com o surgimento do Programa Nacional de Defensivos Agrícolas (PNDA), que subsidiou o crédito e estimulou a implantação de indústrias de defensivos agrícolas no país (ABREU et al., 2017; LOPES et al., 2018).

Os agrotóxicos são produtos constituídos por uma diversidade de compostos químicos e biológicos, tendo especificamente, a função de controlar, extinguir e prevenir agentes patogênicos e ervas daninha em plantações rurais. Quando utilizados, esses agroquímicos podem facilmente desviar sua finalidade primária de combate às espécies-alvo, também conhecidas como "pragas", podendo propagar-se facilmente no ambiente, sendo ainda quimicamente capaz de alcançar a atmosfera e contaminar os locais adjacentes onde ocorreu a sua aplicação, devido, sobretudo a seu potencial de volatização a partir do solo, água e superfície vegetal, podendo variar conforme o seu princípio ativo (SOUZA et al., 2017).

O uso indiscriminado e inadequado dos agrotóxicos agrícolas é um caso peculiar de externalidade negativa tanto para à saúde humana como para o meio ambiente, sendo que os danos à saúde humana podem ocorrer de forma direta através da intoxicação do trabalhador rural durante a aplicação do produto químico ou de forma indireta através da ingestão de alimentos que contenha quantidades de resíduos em níveis prejudiciais à saúde (SOARES et al., 2007). Segundo esses autores, as externalidades negativas dos agrotóxicos sobre o meio ambiente também ocorrem de duas formas, no primeiro caso pode se acumular na biota e no segundo caso pode ocasionar a contaminação dos recursos hídricos e do solo.

As consequências nocivas sobre a saúde humana ocasionada pelo uso indiscriminado de agrotóxicos têm sido alvo de diversas pesquisas elaboradas por profissionais da saúde, onde constataram a presença dessas substâncias químicas em amostras de sangue humano, no leite materno e resíduos presentes em produtos alimentícios consumidos pela população, o que pode resultar em possíveis efeitos negativos ao organismo das pessoas, como a ocorrência de anomalias congênitas, câncer, doenças mentais e de disfunções na reprodutividade humana. Os impactos na saúde, tanto de populações expostas quanto de consumidores, se tornaram tão extensivos, que passaram a representar um problema de saúde pública, amplamente discutido em fóruns de âmbito nacional e internacional (DUTRA et al., 2017; SIQUEIRA et al., 
2008).

Com base no contexto apresentado, objetivou-se desenvolver nesse artigo uma discussão a partir de dados disponíveis na literatura entre o período de 2009 a 2019 sobre o uso intensivo de agrotóxicos nas lavouras brasileiras, visto que o uso desses agroquímicos podem ocasionar graves danos à saúde humana e ao meio ambiente quando não são aplicados de forma adequada.

A modernização da agricultura foi propagada no Brasil desde a metade do século XX com o intuito de aumentar a produção e a produtividade de culturas de interesse internacional mediante a inserção de inovações tecnológicas (MATO et al., 2011). Para os autores, o aperfeiçoamento tecnológico para expansão do setor agrícola no Brasil foi possível em razão de uma conjuntura política conduzida pelo o Estado, através de investimentos em pesquisas científicas, com a criação de órgãos como a EMBRAPA (Empresa Brasileira de Pesquisa Agropecuária), políticas públicas e concessão de créditos agrícolas.

O resultado da política agrícola adotada desde a década de 1960 proporcionou um avanço no agronegócio brasileiro, resultando em uma maior concentração de terra e renda e exigindo cada vez mais a aquisição de elevadas quantidades de produtos agroquímicos para a cultivação de lavouras e controle de pragas agrícolas, o que acabou influenciando na consolidação da produção industrial de defensivos agrícolas no país (ABREU et al., 2016). Segundo esses autores, as políticas de incentivos fiscais e de financiamento público possibilitaram a inserção e implantação de indústrias produtoras de agroquímicos no Brasil, associado à isenção de impostos, como por exemplo, Imposto de Circulação de Mercadoria e Serviços (ICMS), Imposto de Produtos Industrializados (IPI), como também isenção das taxas de importação de produtos produzidos no exterior e a utilização de aviões para flexibilizar as práticas de manejos nas lavouras.

Os termos pesticidas, praguicidas, biocidas, fitossanitários, agrotóxicos, defensivos agrícolas, venenos, remédios expressam as várias denominações dadas a um mesmo grupo de substâncias químicas (SILVA et al., 2005), sendo que os termos "agrotóxicos" ou "agroquímicos" são as expressões mais utilizadas no meio científico. Segundo o decreto 4.074/2002 (BRASIL, 2002), que regulamentou a Lei no 7.802 de 11 de julho de 1989, os agrotóxicos e afins são definidos como sendo produtos e agentes de processos físicos, químicos ou biológicos, destinados ao uso nos setores de produção, no armazenamento e beneficiamento de produtos agrícolas, nas pastagens, na proteção de florestas, nativas ou plantadas, e de outros ecossistemas e de ambientes urbanos, hídricos e industriais, cuja finalidade seja alterar a composição da flora ou da fauna, a fim de preservá-las da ação danosa de seres vivos considerados nocivos, bem como as substâncias e produtos empregados como desfolhantes, dessecantes, estimuladores e inibidores de crescimento.

Para serem comercializados no Brasil, os agrotóxicos precisam ser devidamente registrados e necessita passar ainda por um rigoroso processo de avaliação e classificação quanto à sua eficiência, toxicidade ao ser humano e aos organismos da natureza (como mamíferos, aves, abelhas, peixes e outros organismos aquáticos), visto que todos esses procedimentos exigidos para fins de fiscalização envolvem três ministérios governamentais no Comitê técnico de assessoramento para agrotóxicos: Ministério da Agricultura, Pecuária e Abastecimento (MAPA), Ministério da Saúde (MS) e o Ministério do Meio Ambiente 
(MMA) (SPADOTTO et al., 2010).

Segundo Londres (2011) há isenções fiscais e tributárias que são facultadas até hoje no comércio de agrotóxicos no Brasil, onde o governo federal concede redução de $60 \%$ da alíquota de cobrança de ICMS a todos os agrotóxicos e a isenção completa da cobrança de IPI aos agrotóxicos fabricados a partir de uma lista de dezenas de ingredientes ativos e também a isenção da cobrança de PIS/PASEP (Programa de Integração Social/ Programa de Formação do Patrimônio do Servidor) e de COFINS (Contribuição para o Financiamento da Seguridade Social) a "defensivos agrícolas" classificados na posição 38.08 da NCM (Nomenclatura Comum do Mercosul), que compreende produtos diversos como: fungicida, inseticida e herbicidas, e juntamente com outras isenções estaduais, como por exemplo, o estado do Ceará que oferece a isenção de ICMS, IPI, COFINS e PIS/PASEP para atividades envolvendo agrotóxicos em até $100 \%$, sendo que essas políticas de incentivos têm sido importantes para a expansão do uso de agrotóxicos no Brasil e consequentemente o aumento da produtividade nas lavouras agrícolas.

O mercado brasileiro de agrotóxicos expandiu rapidamente na última década (190\%), num ritmo de crescimento maior que o dobro do apresentado pelo mercado global (93\%), o que coloca o Brasil em primeiro lugar no ranking mundial, desde 2008 (RIGOTTO et al., 2014). De acordo com Instituto Brasileiro do Meio Ambiente e dos Recursos Naturais Renováveis (IBAMA, 2019), as vendas de agrotóxicos e afins no Brasil tiveram um crescimento anual de 194,09\% entre os anos de 2000 e 2012. Entre os anos de 2015 e 2016, a quantidade de produtos agrotóxicos comercializados, expresso em termos de ingredientes ativos (substância que confere eficácia ao produto), apresentou um acréscimo de 3,90\%, passando de 521.525,40 em 2015 para 541.861,09 toneladas de agrotóxicos vendidos no país em 2016. Em 2018, a quantidade de produtos agrotóxicos comercializados totalizou em 549.280,44 toneladas ao ano, o que representa um aumento de 1,7\% de toneladas em relação ao ano de 2017.

\section{METODOLOGIA}

Para elaboração deste trabalho foi realizada uma revisão de literatura, aliada a técnicas descritivas e exploratórias para avaliação dos conteúdos dos artigos, sobre os principais condicionantes que impactam negativamente a saúde humana e ao meio ambiente quando se utiliza agrotóxicos de forma intensiva e indiscriminada no tratamento de lavouras para a produção de produtos agrícolas.

De acordo com Sampaio et al. (2007), a revisão de literatura é uma forma de pesquisa que utiliza como fonte de dados a literatura sobre determinado tema de pesquisa. Os mesmos autores ainda destacam que esse tipo de investigação disponibiliza um resumo das evidências relacionados a determinado fenômeno ou área de estudo, mediante a aplicação de métodos explícitos e sistematizados de busca, apreciação crítica e síntese da informação selecionada. Conforme Gil (2017) a finalidade da pesquisa exploratória é proporcionar uma maior proximidade com o objeto a ser estudado, com vista a torná-los mais explícitos, sendo que o planejamento desse tipo de pesquisa tende a ser flexível em razão de considerar os mais diversos aspectos do fenômeno investigado. A pesquisa descritiva "é aquela que visa apenas a observar, registrar e descrever as características de um determinado fenômeno ocorrido em uma 
amostra ou população, sem, no entanto, analisar o mérito de seu conteúdo" (FONTENELLES et al., 2009).

No desenvolvimento desta pesquisa foram consultados artigos publicados em periódicos nacionais e internacionais presentes nas bases de dados LILACS e ScienceDirect, através da combinação e cruzamento das seguintes palavras-chaves: agrotóxicos (agrotoxics), saúde humana (human health) e contaminação ambiental (environmental contamination), utilizando o operador lógico booleano "AND". Os principais critérios de inclusão que nortearam a escolhas dos trabalhados acadêmicos destacados nesse estudo foram: artigos publicados em periódicos nacionais e internacionais avaliados por pares, redigidos em português e inglês; publicações enquadradas entre o período de 2009 a 2019. Não foram considerados para análise artigos científicos apenas de revisão bibliográficas, sendo apreciados artigos originais e técnicos. Esse estudo também considerou as publicações oficiais divulgados pela Agência Nacional de Vigilância Sanitária - ANVISA, como o Programa de Análise de Resíduos de Agrotóxicos em Alimentos - PARA.

\section{RESULTADOS E DISCUSSÃO}

$\mathrm{Na}$ busca realizada nas plataformas digitais citadas, foram inicialmente identificados 247 artigos na base de dados LILACS e 722 na ScienceDirect, totalizando 969 artigos pesquisados. Em seguida foram analisados os títulos, resumos, metodologias e todo o conteúdo do artigo para verificar adequação a proposta de pesquisa, sendo que na base LILACS foram selecionados 27 artigos e na ScienceDirect 4 artigos, que juntos totalizaram em 31 achados para serem utilizados neste estudo científico baseado em evidências.

Os periódicos que tiveram mais representatividade foram: Ciência \& Saúde Coletiva com 29\% (n=9) dos achados; Revista Brasileira de Saúde Ocupacional com 9,7\% (n=3); Revista Brasileira de Enfermagem com 6,5\% ( $n=2)$; Revista de Ecotoxicologia e Meio Ambiente com 6,5\% ( $n=2)$; Ciência Rural com 6,5\% ( $n=2)$; Acta Scientiarum - Health Sciences com 6,5\% ( $n=2)$; e a Food Chemistry também com 6,5\% ( $n=2)$, sendo que os restantes dos periódicos tiveram menos de $4 \%$ de representatividade nos achados. As principais bases de dados indexadas nos periódicos citados são: SCOPUS (Reed Elsevier), SCIELO (Scientific Electronic Library Online) e Web of Science (Clarivate Analytics). Outra característica referente aos achados científicos é que os mesmos utilizaram metodologias com predominância de abordagem qualitativa aliada a técnicas estatísticas. No quadro a seguir pode ser verificado os resultados das buscas que foram realizadas nas duas bases de dados LILACS e ScienceDirect.

Quadro 1: Distribuição das referências bibliográficas consultadas

\begin{tabular}{|c|l|c|c|}
\hline Base de Dados & \multicolumn{1}{|c|}{ Palavras-chave cruzadas } & Referências obtidas & Referências selecionadas \\
\hline \multirow{5}{*}{ LILACS } & (agrotóxicos) and (saúde humana) & 44 & 13 \\
& (agrotóxicos) and (contaminação ambiental) & 41 & 12 \\
& (contaminação ambiental) and (saúde humana) & 69 & 1 \\
& (human health) and (agrotoxics) & 43 & 1 \\
& (environmental contamination) and (agrotoxics) & 1 & 0 \\
& (environmental contamination) and (health) & 50 & 1 \\
\hline \multirow{5}{*}{ ScienceDirect } & (human health) and (agrotoxics) & 19 & 1 \\
& (environmental contamination) and (agrotoxics) & 677 & 2 \\
& (environmental contamination) and (human) health) & 1 & 0 \\
& (agrotóxicos) and (saúde humana) & 0 & 0 \\
\hline & (agrotóxicos) and (contaminação ambiental) & 5 & 0 \\
\hline
\end{tabular}


Conforme os resultados obtidos pelo Programa de Análise de Resíduos de Agrotóxicos em Alimentos - PARA, divulgados pela Anvisa, durantes os anos de 2009 e 2010 ocorreu um decréscimo no total de amostras de alimentos com Limite Máximo de Resíduo - LMR (expresso em miligrama de resíduo por quilograma de alimento) em $1,1 \%$, sendo que nesse período os alimentos como mamão (ingrediente ativo encontrado: carbendazim e procloraz) e abacaxi (ingrediente ativo encontrado: carbendazim) apresentaram os maiores percentuais de ingredientes ativos acima do nível permitido, visto que o limite máximo de resíduo é bastante variável dependendo da substância ativa presente e do seu grau de intoxicação como, por exemplo, carbendazim onde a taxa aceitável deve ser menor que $5 \mathrm{mg} / \mathrm{kg}$. Em 2011, o percentual de amostras de alimentos com LMR teve um acréscimo em relação ao ano anterior em $8,1 \% \mathrm{e}$ posteriormente apresentou uma redução significativa no período de 2012 a 2015, em cerca de 16\% no LMR. Os principais ingredientes ativos com maior representatividade durante esse período foram da classe dos fungicidas (carbendazim) e inseticidas (clorpirifós), tendo destaque nos alimentos como: mamão, uva, tomate e pimentão (ANVISA, 2010, 2011, 2013, 2016).

Entre o período de 2017 a 2018, 49\% das 4.616 amostras de alimentos analisadas não apresentaram resíduos agrotóxicos, sendo que $28 \%$ das amostras apresentaram resíduos dentro do LMR e 23\% das amostras analisadas tiveram taxas de resíduos maiores que o limite máximo aceitável. As principais culturas que apresentaram ingrediente ativo maior que o nível aceitável foram: pimentão contendo $41,72 \%$ de acefato e $34,36 \%$ de metomil acima do LMR nas amostras; tomate contendo acefato com $21,20 \%$; e cenoura contendo clorpirifós com $24,93 \%$ e acefato com $13,88 \%$. Durante esse período acefato teve maior representatividade nas amostras de alimentos, sendo que o LMR para esse agente ativo é de $0 \mathrm{mg} / \mathrm{kg}$ (ANVISA, 2019).

Quadro 2: Relação dos artigos científicos selecionados para revisão

\begin{tabular}{|c|c|c|}
\hline AUTOR & ANO & TíTULO \\
\hline Dalbó et al. & 2019 & Effects of pesticides on rural workers: haematological parameters and symptomalogical reports \\
\hline Corcino et al. & 2019 & Avaliação do efeito do uso de agrotóxicos sobre a saúde de trabalhadores rurais da fruticultura irrigada \\
\hline Buralli et al. & 2018 & Respiratory condition of family farmers exposed to pesticides in the state of Rio de Janeiro, Brazil \\
\hline Oliveira et al. & 2018 & $\begin{array}{l}\text { Processo sócio-sanitário-ambiental da poluição por agrotóxicos na bacia dos rios Juruena, Tapajós e Amazonas em } \\
\text { Mato Grosso, Brasil }\end{array}$ \\
\hline Almeida et al. & 2017 & Uso de sementes geneticamente modificadas e agrotóxicos no Brasil: cultivando perigos \\
\hline Soares et al. & 2017 & $\begin{array}{l}\text { Análise de risco de contaminação de águas subterrâneas por resíduos de agrotóxicos no município de Campo Novo do } \\
\text { Parecis (MT), Brasil }\end{array}$ \\
\hline Almeida et al. & 2017 & $\begin{array}{l}\text { A flexibilização da legislação brasileira de agrotóxicos e os riscos à saúde humana:análise do Projeto de Lei no } \\
3.200 / 2015\end{array}$ \\
\hline Pignati et al. & 2017 & Distribuição espacial do uso de agrotóxicos no Brasil: uma ferramenta para a vigilância em saúde \\
\hline Shinohara et al. & 2017 & Insegurança alimentar no uso indiscriminado de agrotóxicos \\
\hline Cezar-Vaz et al. & 2016 & Socio-environmental approach in nursing: focusing on rural labor and the use of pesticides \\
\hline Borges et al. & 2016 & Agricultura familiar e a conservação da saúde humana e ambiental \\
\hline Viero et al. & 2016 & Risk society: the use of pesticides and implications for the health of rural workers \\
\hline Andrade et al. & 2015 & $\begin{array}{l}\text { Liquid chromatography-electrospray ionization tandem mass spectrometry and dynamic multiple reaction monitoring } \\
\text { method for determining multiple pesticide residues in tomato }\end{array}$ \\
\hline Casali et al. & 2015 & Nível de capacitação e informação dos operadores de máquinas para a aplicação de agrotóxicos \\
\hline Siqueira et al. & 2014 & Análise da exposição de Trabalhadores rurais a agrotóxicos \\
\hline $\begin{array}{l}\text { Faria, Fassa e } \\
\text { Meucci }\end{array}$ & 2014 & Association between pesticide exposure and suicide rates in Brazil \\
\hline $\begin{array}{l}\text { Nasrala Neto et } \\
\text { al. }\end{array}$ & 2014 & Vigilância em saúde e agronegócio: os impactos dos agrotóxicos na saúde e no ambiente. Perigo à vista! \\
\hline Pignati et al. & 2014 & $\begin{array}{l}\text { Vigilância aos agrotóxicos: quantificação do uso e previsão de impactos na saúde-trabalho-ambiente para os municípios } \\
\text { brasileiros }\end{array}$ \\
\hline Tofolo et al. & 2014 & Contributing factors for farm workers' exposure to pesticides in the west of the state of Santa Catarina, Brazil \\
\hline Rigotto et al. & 2013 & Tendências de agravos crônicos à saúde associados a agrotóxicos em região de fruticultura no Ceará, Brasil \\
\hline Santos et al. & 2013 & Avaliação da contaminação de corpos d'água adjacentes a áreas agrícolas da Ilha de São Luís (MA) por agrotóxicos \\
\hline
\end{tabular}




\begin{tabular}{|l|l|l|}
\hline Carneiro et al. & 2013 & $\begin{array}{l}\text { Development and method validation for determination of 128 pesticides in bananas by modified QuEChERS and UHPLC- } \\
\text { MS/MS analysis }\end{array}$ \\
\hline Pontes et al. & 2013 & $\begin{array}{l}\text { Os perímetros irrigados como estratégia geopolítica para o desenvolvimento do semiárido e suas implicações à saúde, } \\
\text { ao trabalho e ao ambiente }\end{array}$ \\
\hline Detófano et al. & 2013 & $\begin{array}{l}\text { Evaluation of toxicity risks in farmers exposed to pesticides in an agricultural community in Concórdia, Santa Catarina } \\
\text { State, Brazil }\end{array}$ \\
\hline Martini et al. & 2012 & $\begin{array}{l}\text { Risco de contaminação das águas de superfície e subterrâneas por agrotóxicos recomendados para a cultura do arroz } \\
\text { irrigado }\end{array}$ \\
\hline Moreira et al. & 2012 & Contaminação de águas superficiais e de chuva por agrotóxicos em uma região do estado do Mato Grosso \\
\hline Ruy et al. & 2012 & Risco de contaminação por agrotóxicos das águas subterrâneas em áreas cultivadas com cana-de-açúcar \\
\hline Pessoa et al. & 2012 & $\begin{array}{l}\text { Agronegócio: geração de desigualdades sociais, impactos no modo de vida e novas necessidades de saúde nos } \\
\text { trabalhadores rurais }\end{array}$ \\
\hline Belo et al. & 2012 & $\begin{array}{l}\text { Uso de agrotóxicos na produção de soja do Estado do Mato Grosso: um estudo preliminar de riscos ocupacionais e } \\
\text { ambientais }\end{array}$ \\
\hline Cesarino et al. & 2012 & $\begin{array}{l}\text { Electrochemical detection of carbamate pesticides in fruit and vegetables with a biosensor based on } \\
\text { acetylcholinesterase immobilised on a composite of polyaniline-carbon nanotubes }\end{array}$ \\
\hline Preza et al. & 2012 & $\begin{array}{l}\text { Vulnerabilidades de trabalhadores rurais frente ao uso de agrotóxicos na produção de hortaliças em região do } \\
\text { Nordeste do Brasil }\end{array}$ \\
\hline
\end{tabular}

No Brasil consta em tramitação no congresso nacional o Projeto de Lei (PL) no. 3.200/2015 que teve como principal fundamento a PL no. 6.299/2002, que visa a modernização do agronegócio brasileiro com vista a torná-lo mais produtivo e lucrativo, através da desburocratização e substituição de antigos marcos jurídicos, tendo como finalidade flexibilizar a liberação de novos agroquímicos, dentre outros fins. Almeida et al. (2017) analisando os projetos de leis em curso no congresso nacional, através de um estudo reflexivo, destacou os diversos retrocessos da (PL) 3.200/2015 em relação a temática dos agrotóxicos no Brasil, tendo em pauta propostas para alterações das leis já existente sobre essa temática, como Lei $n^{\circ}$. 7.802/1989, regulamentada pelo Decreto $n^{\circ}$ 4.074/2002 que substituiu os decretos $n^{\circ}$. 24.114/1934 e no. 98.816/1990.

Conforme Almeida et al. (2017) a PL no 3.200/2015 limitou a competência dos estados e do Distrito federal de fiscalizar o comércio e consumo de agrotóxicos e de constituírem leis próprias de regulação desses produtos, bem como suprimiu o poder de decisão dos Ministérios da Saúde - MS e do Meio Ambiente - MMA quanto ao processo de registros de novos agroquímicos, sendo que antes da responsabilidade de registrar agrotóxicos necessitava-se do deferimento das três instituições de forma autônoma: MAPA, MS, MMA, visto que a PL propõe uma maior centralidade de poder decisório no âmbito da Comissão Técnica Nacional de Fitossanitários (CTNFito), vinculada ao MAPA, excluindo várias atribuições específicas do MS e MMA. Os autores ressaltam também que o termo "agrotóxico" foi substituído por outro termo denominado "produto defensivo fitossanitário", o que permite amenizar ou anular o conceito de toxicidade atribuído a essas substâncias químicas e pode transmitir uma ideia de que são totalmente inofensivos à saúde humana e ao meio ambiente. Para os autores a "PL 3.200/2015 preza por questões econômicas do mercado produtor de agrotóxicos e contribuirá para maximizar os impactos sociais e ambientais de curto, médio e longo prazos [...]".

Cezar-Vaz et al. (2016) ao analisar o cotidiano laboral de 331 trabalhadores rurais em dois municípios do estado do Rio Grande do Sul, com idades variando de 18 a 81 anos, através de uma abordagem socioambiental (por regressão de Poisson) para averiguação de nexo/associação entre distúrbios de saúde e uso de agroquímicos, constataram que todos os trabalhadores rurais fazem uso de agrotóxicos, sendo que 47,4\% realizam a pulverização dessas substâncias e 52,6\% apenas auxiliam durante a aplicação. Os principais agrotóxicos utilizados pelos trabalhadores foram: pesticidas (acefato) e inseticida (deltrametrina) por $52,2 \%$ dos entrevistados; $35,84 \%$ dos entrevistados faziam uso de herbicida 2,4-D 
(ingrediente ativo glifosato), que é uma substância ligeiramente perigosa; 1,25\% utilizavam agroquímicos a base de metil paration, extremamente perigoso; e 0,9\% usavam agrotóxicos a base de cipermetrina, considerado um princípio ativo bastante perigoso. Casali et al. (2015) verificaram o nível de conhecimento dos operadores com relação ao manejo de produtos químicos e máquinas destinadas a pulverização desses produtos na região central do Rio Grande do Sul, onde observaram que os operadores que realizam cursos com carga horária maior que 20 horas apresentam nível de instrução de 50\% maior, quando comparado aos operadores que realiza cursos com carga horária menor que 20 horas. Nessa região ficou constatado por esses autores que o nível de conhecimento dos operadores de máquinas que realizam as atividades de pulverização de agrotóxicos pode ser considerado insuficiente para o manejo correto dessas substâncias.

Ficou constatado também conforme Cezar-Vaz et al. (2016) que apesar da maioria dos trabalhadores utilizarem EPIs (Equipamentos de Proteção Individuais) apropriados, ainda foram registrados agravos à saúde como: transtornos mentais $(n=206,62,2 \%)$, seguido por distúrbios circulatórios $(n=165$, $49,8 \%$ ), dermatológicos ( $n=149,45 \%)$, respiratórios ( $n=136,41 \%)$ e gástricos $(n=120,36,2 \%)$. Ainda conforme os autores, trabalhadores que aplicam esses produtos apresentam prevalência de $90 \%$ para desenvolverem alterações dermatológicas quando comparados aos que não fazem a aplicação de agrotóxicos.

Tofolo et al. (2014) ao analisarem o risco de toxicidade em agricultores expostos a agrotóxicos no município de Marema - SC, observaram que os agricultores que possuem baixo nível de educação formal necessitam de informações técnicas sobre a aplicação correta desses agroquímicos desde o momento de aquisição do produto até a destinação final das embalagens vazias, visto que as práticas adotadas por esses produtores corroboram para a instalação de danos ambientais e problemas de saúde.

No estudo qualitativo desenvolvido por Borges et al. (2016) na Ilha dos Marinheiros, Rio Grande RS com 129 trabalhadores familiares (tendo predominância indivíduos do sexo masculino) buscou-se compreender como esses trabalhadores identificam os impactos negativos e positivos em relação à conservação ambiental. Ficou constatado entre os impactos positivos: a geração de alimentos com responsabilidade; a valorização do trabalho; a correta, mínima ou nula utilização dos agrotóxicos; entre os aspectos negativos, o uso excessivo e incorreto dos agrotóxicos e a ausência de conhecimentos para desenvolvimento da atividade. Segundo Shinohara et al. (2017) a comercialização de alimentos sem obedecer ao período de carência (após utilização de substâncias químicas) pode ocasionar doenças ocupacionais em trabalhadores rurais e também coloca em risco populações urbanas, sendo que os casos de intoxicação aguda e crônica podem evoluir para quadros clínicos de fraqueza, alergias, náuseas ou mesmo reações mais graves como lesões hepáticas, neoplasias, efeitos neurotóxicos e outros sintomas de acordo com a frequência de exposição a pesticidas agrícolas.

Siqueira et al. (2014) ao analisar o uso e manuseio de agrotóxicos por trabalhadores rurais de dez comunidades do município de Vitória de Santo Antão-PE, constatou que dos 230 trabalhadores rurais (faixa etária de 21 a 50 anos) entrevistados (com predominância de mulheres) 61,3\% ( $n=141$ ) aplicavam o produto sem orientações técnicas, sendo que somente $0,9 \%(n=3)$ eram orientados por especialistas. Dos 
entrevistados, segundo os autores, $28,3 \%$ ( $n=97)$ não têm conhecimento sobre o intervalo de segurança de aplicação dos agrotóxicos, 19,5\% ( $n=67)$ não tinham conhecimento sobre a importância da reciclagem das embalagens desses produtos químicos, $23,3 \%(n=80)$ utilizam os rios para lavagem dos equipamentos e $31,5 \%(n=108)$ reutilizam as sobras desses agroquímicos, além disso, $27,7 \%(n=95)$ realizavam as atividades sem cuidados com a sua saúde. O desconhecimento das precauções de segurança quanto a utilização de agrotóxicos em relação ao meio ambiente e a própria saúde são fatores que refletem a precariedade na forma que essas atividades agrícolas estão sendo desenvolvidas na atualidade.

Pessoa et al. (2012) destacaram em seu estudo realizado na Chapada do Apodi, em 2010, com um grupo de trabalhadores de uma equipe de saúde da família (médico, enfermeiro, agente comunitário de saúde, auxiliar de enfermagem), dois usuários do Sistema Único de Saúde (SUS), auxiliar de serviços gerais, trabalhador rural do agronegócio, presidente da associação dos trabalhadores rurais, conselheira municipal de saúde, vereador, professora e dois representantes dos movimentos sociais, a realização de entrevistas sobre as necessidades de saúde dos trabalhadores rurais no agronegócio. Os autores ressaltaram que o grupo entrevistado foi unanime em relação à importância da agricultura para geração de alimentos, de emprego e renda para as famílias, no entanto, a grande maioria tem consciência de que a terra está sendo utilizada de forma incorreta, principalmente, pelos grandes empreendimentos agrícolas, e que isso pode provocar em um curto período de tempo, a perda da produtividade em razão dos graves problemas ambientais ocasionados pelo agronegócio.

Para Pessoa et al. (2012) a agricultura hoje em dia apresenta uma dicotomia, onde por um lado há uma forte dependência da terra como fonte de sobrevivência, mesmo que isto acarrete repercussões negativas sobre a qualidade de vida futuramente. Para os autores a produção de alimentos, sob a perspectiva da promoção da saúde, deveria estar comprometida com a soberania alimentar para que haja melhores condições de vida para a população global. Corcino et al. (2019) ao realizar entrevista com 339 trabalhadores das culturas de frutas nos municípios de Juazeiro - BA e Petrolina - PE com o intuito de avaliar o impacto do uso de agrotóxicos sobre a saúde humana, constataram que muitos desses agricultores sabem da importância do uso de EPIs e da obrigatoriedade do receituário agronômico para realizar a aquisição e utilização de agroquímicos, no entanto, $40 \%$ não fazem uso adequado dos equipamentos de proteção e $28,9 \%$ não apresentam receituário durante a compra.

A negligência quanto ao uso correto dos agrotóxicos nas lavouras agrícolas é considerada um dos principais entraves no que tange a minimização dos efeitos negativos provocados por essas substâncias químicas para saúde humana e para o meio ambiente no Brasil, que apesar do país possuir legislações especificas como a Norma Regulamentadora - NR 31 para auxiliar na saúde e segurança dessa classe trabalhadora, as evidências científicas comprovam que na prática há pouca preocupação quanto a esse contexto pelos próprios usuários de agrotóxicos. Viero et al. (2016) realizou uma entrevista com 15 trabalhadores rurais em um município do estado do Rio Grande do Sul para verificar a percepção que tais indivíduos têm em relação aos riscos que os agrotóxicos impõem a saúde humana, onde concluiu que os agricultores conhecem os riscos relacionados ao uso de agrotóxicos para sua saúde e não fazem a utilização dos equipamentos de proteção individual. 
Soares et al. (2017) em seu estudo sobre a contaminação das águas subterrâneas por resíduos de agrotóxicos utilizados nas diversas culturas presente na região que está localizada na cidade de Campo Novo do Parecis no estado do Mato Grosso (MT), verificou que os solos da região apresentam características físico-químicas favoráveis a percolação de princípios ativos presentes em agrotóxicos, o que contribui para o aumento do risco de contaminação das águas do subsolo. Conforme os autores, dos 114 tipos de agrotóxicos comercializados na região $45,6 \%$ estão enquadrados nas classes I e II da tabela de classificação de agroquímicos, sendo considerados produtos "altamente perigosos" e "muito perigosos" ao meio ambiente. Ainda conforme os autores, os ingredientes ativos como ciproconazol, clomazone, lactofem, tiametoxam, dentre outros, apresentam características que favorecem o transporte de contaminação, enquanto que azoxistrobina, b-ciflutrina, clorpirifos, endossulfam, tiofanato-metilico, dentre outros, apresentam características desfavoráveis ao transporte. Os agrotóxicos passaram a ser classificados no Brasil pela GHS (Sistema Globalmente Harmonizado de Classificação e Rotulagem de Produtos Químicos), adotado em vários países do globo, no qual foi estabelecido pela nova resolução da ANVISA no. 296 de 29 de julho de 2019 (ANVISA, 2019).

Pignati et al. (2017) ao verificarem os dados de área plantada em 21 culturas predominantes no Brasil em relação ao uso de agrotóxicos e as incidências de intoxicações por esses produtos, constataram que os cultivares de soja, milho e cana totalizam $76 \%$ de área plantada no país desde 2015 , sendo que foram pulverizados 899 milhões de litros de agrotóxicos nessas lavouras, tendo predominância dos estados de Mato Grosso, Paraná e Rio Grande do Sul. Para os autores, os agravos à saúde humana apresentaram correlações positivas e significativas com o uso de agrotóxicos. Dalbó et al. (2019) analisaram a população rural composta por 142 trabalhadores no município de Conceição do Castelo - ES em relação aos sintomas clínicos e alterações hematológicas, onde 22 desses trabalhadores foram selecionados de forma randomicamente. Conforme os autores, "as variações nas concentrações de bastonetes e neutrófilos indicam que a exposição a pesticidas aumenta a quantidade dessas células", o que pode estar correlacionados aos sintomas citados pela maioria dos trabalhadores como irritação nos olhos, dores de cabeça, dores nas articulações e nos músculos.

Detófano et al. (2013) ao analisarem o risco de toxicidade em 50 agricultores rurais (através de questionário) da comunidade da Linha São Paulo, município de Concórdia - SC expostos a agrotóxicos, verificaram que existe diversas situações e procedimentos que coloca em vulnerabilidade boa parte dos agricultores a riscos de intoxicação, em razão dessas pessoas não possuírem informações sobre biossegurança e por não terem entendimento adequado sobre o uso desses produtos químicos, o que fica evidente a forte carência na veiculação de informações acerca dos produtos. Os autores constataram que 72\% dos entrevistados afirmaram que sentem desconfortos ao utilizarem os agrotóxicos como: $31,9 \%$ sentem dores de cabeça; $12,5 \%$ têm desconforto geral; $11,1 \%$ sentem náuseas, tonturas e sensação de queimação no nariz; $6,67 \%$ sentem problemas de eritema facial; $44,4 \%$ tosse; e $2,2 \%$ alergias.

Segundo Detófano et al. (2013) o monitoramento da exposição a agroquímicos pode minimizar o percentual de indivíduos envenenados, prevenir novos casos e reduzir a gravidade do nível de intoxicação. 
Buralli et al. (2018) analisando se a exposição a agrotóxicos está associada a desfechos respiratórios em um grupo de 82 trabalhadores rurais e familiares no Brasil durante a safra e entressafra, constataram que os mesmos apresentaram prevalências de $40 \%$ e $30,7 \%$ para tosse, $30,7 \%$ e $24 \%$ para alergia nasal e $24 \%$ e 17,3\% para opressão torácica. Rigotto et al. (2013) observaram em seu estudo que ocorreu uma maior mortalidade por neoplasias nos municípios cearenses que apresentaram maior consumo de agrotóxicos nas lavouras de cultivos de frutas, "podendo ser influenciados pelas transformações produtivas, ambientais e sociais associadas ao processo de desterritorialização induzido pela expansão da modernização agrícola $[\ldots]^{\prime \prime}$.

Analisando a contaminação da água da chuva e águas subterrâneas nos municípios de Lucas do Rio Verde e Campo Verde no Mato Grosso (MT), situado entre os maiores produtores de soja, milho e algodão do estado, Moreira et al. (2012) constataram que as amostras de água apresentaram resíduos de diferentes agrotóxicos tanto nas águas superficiais como nas águas das chuvas nos dois municípios. No município de Lucas do Rio Verde nas amostras de 62 poços de água analisadas foi constatado uma maior prevalência de substâncias químicas como endosulfan alfa e beta, flutriafol e metolacloro, visto que em relação às águas das chuvas das 104 amostras 56\% apresentaram pelo menos três tipos diferentes de resíduos químicos, tendo prevalência nos resíduos com compostos químicos contendo atrazina em $43 \%$ das amostras e o flutriafol em $51 \%$ das amostras. Já em Campo Verde, cerca de $50 \%$ das amostras de água de poços coletados tiveram resíduos de agrotóxicos em concentrações que variam de 0,18 $\mu \mathrm{g} / \mathrm{L}$ a $18,96 \mu \mathrm{g} / \mathrm{L}$, e as águas das chuvas tiveram prevalência de atrazina em 31 amostras.

Martini et al. (2012) ao estimarem a probabilidade de contaminação de águas subterrâneas e superficiais por agrotóxicos, através de parâmetros preestabelecidos e modelo matemático, concluiram que "alguns resultados de monitoramentos confirmam a tendência do comportamento de certos agrotóxicos no ambiente". Ao realizar uma pesquisa semelhante de simulação da lixiviação de agrotóxicos utilizados na cultura da cana-de-açúcar no município de Bandeirantes (PR), Ruy et al. (2012) observaram que somente os seguintes compostos químicos possuem potencial de contaminação de águas subterrâneas: hexazinona, diuron, tebutiron e sulfentrazona.

Ao realizarem um levantamento sobre os principais agrotóxicos utilizados por agricultores na zona rural da Ilha de São Luís (MA), Santos et al. (2013) verificaram que os agrotóxicos averiguados apresentam riscos de contaminação ambiental, sendo que em algumas das amostras de água foi detectada a presença de agrotóxico organoclorado. Esses autores destacam ainda que ocorreu uso predominante dos inseticidas organofosforados (OP), piretroides e pelo herbicida glifosato. Além disso, um dos graves problemas citados pelos autores foi em relação ao destino, descarte e reutilização das embalagens dessas substâncias químicas, que não estão realizados de forma adequada por tais produtores rurais.

Ao verificar o impacto dos perímetros irrigados como estratégia geopolítica para expansão da fronteira agrícola brasileira e o "desenvolvimento" do semiárido nordestino, mais especificamente na Chapada do Apodi - RN entre os anos de 2007 a 2011, Pontes et al. (2013) constataram que a expansão do agronegócio pelo incremento de grandes empresas transnacionais e nacionais de fruticultura para exportação, provocou a contaminação ambiental e humana pelo uso indiscriminado de substâncias 
químicas nos cultivares pelo agronegócio, através da prática de pulverizações aéreas. Esses autores ressaltaram que em relação à saúde humana, o agronegócio tem ocasionados profundas modificações no modo de vida da população loca, desde o aumento de violência, inserção de drogas junto a escolares, prostituição e migração.

Destacam-se também conforme Pontes et al. (2013) constantes desapropriações de terras camponesas por pressão dos grandes latifundiários e vínculos de trabalhistas em períodos sazonais de até seis meses, caracterizado como modelo de produção com intensa exposição a agrotóxicos e fertilizantes.

Oliveira et al. (2018) analisando o processo de poluição ambiental por agrotóxicos nos municípios de Campo Novo do Parecis, Sapezal e Campos de Júlio, em Mato Grosso, verificaram um intenso processo de poluição química provocado pelos latifúndios, com elevado uso de agroquímicos por habitantes com cerca de 600 L/hab e da utilização do herbicida com princípio ativo "glifosato" nas lavouras de soja transgênica com um volume de $45 \%$ do total de agrotóxicos utilizados, bem como as recentes liberações do uso do inseticida a base de benzoato de emamectina e de sementes de soja e milho geneticamente modificada resistentes ao herbicida 2,4-D. A produção de soja no estado do Mato Grosso aparece como fator gerador de riscos à saúde do trabalhador rural e dos habitantes do entorno de áreas produtivas, principalmente no que diz respeito à exposição a agrotóxicos (BELO et al., 2012).

As sementes geneticamente modificadas da multinacional Monsanto são desenvolvidas para serem resistentes ao herbicida Roundup, substância química que mata qualquer tipo de erva daninha que nascem nas plantações, no entanto, não provoca danos as plantações transgênicas, o que trouxe aumento na utilização de agrotóxicos nas lavouras rurais, inclusive, herbicida a base de glifosato (substância tóxica à saúde humana e ao meio ambiente). Segundo Almeida et al. (2017) em seu estudo sobre uso de agrotóxicos e sementes geneticamente modificadas no Brasil, verificou-se que as culturas de soja, milho e algodão concentram $65 \%$ do total de agrotóxicos utilizados no país, sendo que a soja tem uma maior predominância para sementes transgênicas com volume de $71 \%$. Para esses autores as culturas que utilizam sementes geneticamente modificadas contribuíram para o aumento do uso de agrotóxicos no Brasil e, consequentemente, tem colaborado para exposição humana e ambiental a essas substâncias químicas. De acordo com Pignati, Oliveira e Silva (2014) um hectare de soja consome 12 litros de agrotóxicos, o de milho 6 litros, o de cana 4,8 litros e o de algodão 24 litros.

Faria et al. (2014) analisaram a associação entre o uso de agrotóxicos e o aumento da taxa de suicídio nas 558 microrregiões brasileiras, através de um estudo estátistico por correlação de Pearson e regressão linear múltipla ajustada para fatores socioeconômicos, demográficos e culturais, onde foi constatado que a taxa média de suicídios foi de 6,4 casos/100.000 habitantes por ano no período de 20062010, com uma relação homem/mulher de 4,2. Os autores ressaltaram que havia taxas mais altas de suicídio entre mulheres de 35 a 64 anos e entre homens 15 a 34 anos, sendo que as microrregiões com maior utilização dessas substâncias químicas e com elevadas proporções de intoxicação por agrotóxicos apresentaram as maiores taxas de suicídio para os três grupos analisados: ambos os sexos, homens e mulheres, o que reforça a hipótese que o uso intensivo de agroquímicos aumenta a possibilidade de 
suicídios.

Carneiro et al. (2013) ao realizarem uma análise multirresíduo para a quantificação de 128 pesticidas em banana, através de um procedimento de cromatografia líquida de ultra alto desempenho acoplada a espectrometria de massa tandem, verificou traços de azoxistrobina, carbendazina e tebuconazol em 4 amostras de bananas, enquanto boscalide, carbendazina e imidaclopride foram quantificados em 2 amostras (1 e 9). Conforme os autores, outras 7 amostras ( 1 a 7$)$ não estavam em conformidade com a legislação brasileira, devido ao boscalide e o carbendazin que não são permitidos na cultura de banana, enquanto que 1 amostra (9) nove foi positiva, mas com concentração de imidaclopride menor que o LMR.

Cesarino et al. (2012) ao analisarem amostras de frutas e vegetais (maçã , brócolis e repolho) com intuito de verificarem vestígios de agrotóxicos a base de carbamatos, através de biossensor eletroquímico de acetilcolinesterase, observaram limites de detecção de 1,4 e $0,95 \mu \mathrm{molL}^{-1}$, respectivamente para carbaril e metomil, visto que "esses limites de deteç̧ão estavam abaixo das concentrações permitidas estabelecidas pelos padrões da regulamentação brasileira para as amostras nas quais esses pesticidas foram analisados". Utilizando métodos semelhantes para verificar vestígios de 57 substâncias químicas em tomates, Andrade et al. (2015) verificaram que das 58 amostras de tomate analisadas, mais de $84 \%$ dos compostos apresentaram limites de resíduos iguais ou inferiores a $5 \mathrm{mgkg}^{-1}$. Além disso, doze agrotóxicos foram detectados em 35 amostras, todas abaixo dos limites máximos de resíduos permitidos pela legislação brasileira.

\section{CONCLUSÃO}

O Brasil segue um modelo de produção capitalista neoliberal onde tem por base o emprego intensivo de agrotóxicos no setor agrícola, tendo como objetivo o aumento da produtividade agrícola e das exportações nacionais. A pulverização aérea e a biotecnologia foram um dos principais condicionantes que promoveram o aumento do uso de substâncias químicas no agronegócio brasileiro, através da utilização de sementes geneticamente modificadas, as chamadas sementes transgênicas, que além de proporcionar uma maior produção, é resistente ao herbicida 2,4-D (ingrediente ativo glifosato). Nas culturas contendo sementes transgênicas, os agricultores podem utilizar agrotóxicos antes e depois da plantação sem se preocupar em agredir os seus cultivares.

O herbicida Roundup a base de glifosato é um dos agroquímicos mais utilizados no Brasil, principalmente nas culturas de soja e milho, considerado um tipo de veneno letal para qualquer tipo de erva daninha que possa surgir nas lavouras e ligeiramente perigoso para a saúde humana e ambiental. De um modo geral, as evidências científicas comprovam que o uso de agrotóxicos nos cultivares para produção de commodities agrícolas é extremamente danosa ao ambiente e à saúde humana por contaminarem o solo, as águas superficiais e subterrâneas e os próprios alimentos, tornando-se um grave problema de saúde pública por ocasionar situações adversas de intoxicação alimentar e por elevar a taxa de morbidade em humanos.

No entanto, devido a terra ser uma fonte de geração de emprego e renda, os trabalhadores rurais têm se colocado em exposição a uma diversidade de substâncias químicas. E apesar de boa parte desses 
trabalhadores rurais terem a consciência sobre a correta forma de utilização dos agroquímicos em suas lavouras e as não pôr em prática, torna-se um cenário preocupante. Observa-se que esses trabalhadores ainda estão num patamar de baixo teor de sustentabilidade ambiental e principalmente com elevados índices de agravos a saúde nessa classe trabalhadora, devido, sobretudo aos elevados níveis de exposição química, muitas vezes, de forma negligente. Também foi possível constatar através desse estudo de revisão, que grande parte dos agricultores não utiliza EPIs durante aplicação dos produtos agrotóxicos em suas plantações.

Sabe-se que a prática da logística reversa para embalagens contendo produtos químicos com grande potencial de contaminação ambiental é um ato de grande relevância para preservação dos ecossistemas naturais e também um ato obrigatório pela legislação nacional. Porém, é possível observar que a grande maioria dos produtores rurais de pequeno porte não possui conhecimento desses deveres, visto que muitos não buscam instruções técnicas dos especialistas sobre essa temática (principalmente ao profissional formado em agronomia), os mesmos detêm apenas dos conhecimentos fornecidas pelos comerciantes de agrotóxicos.

\section{REFERÊNCIAS}

ABREU, R. M.; TAVARES, F. G.. Panorama do uso de agrotóxicos na Bahia: desafios para a vigilância à saúde. Revista Baiana de Saúde Pública, v.40, n.2, p.1-113, 2017. DOI:https://doi.org/10.22278/23182660.2016.v40.nS2.a269 $\underline{6}$

ANVISA. Agência Nacional de Vigilância Sanitária. Programa de Análise de Resíduos de Agrotóxicos em Alimentos (PARA): relatório de atividades de 2009. Brasília: ANVISA, 2010.

ANVISA. Agência Nacional de Vigilância Sanitária. Programa de Análise de Resíduos de Agrotóxicos em Alimentos (PARA): relatório de atividades de 2010. Brasília: ANVISA, 2011.

ANVISA. Agência Nacional de Vigilância Sanitária. Programa de Análise de Resíduos de Agrotóxicos em Alimentos (PARA): Relatório de atividades de 2011 e 2012. Brasília: ANVISA, 2013.

ANVISA. Agência Nacional de Vigilância Sanitária. Programa de Análise de Resíduos de Agrotóxicos em Alimentos (PARA): relatório de atividades de 2013 a 2015. Brasília: ANVISA, 2016.

ANVISA. Agência Nacional de Vigilância Sanitária. Programa de Análise de Resíduos de Agrotóxicos em Alimentos (PARA): relatório das amostras analisadas no período de 2017-2018. Brasília: ANVISA, 2019.

ANVISA. Agência Nacional de Vigilância Sanitária. Resolução da diretoria colegiada. Brasília: ANVISA, 2019.

ALMEIDA, V. E. S.; FRIEDRICH, K.; TYGEL, A. F.; MELGAREJO, L.; CARNEIRO, F. F.. Uso de sementes geneticamente modificadas e agrotóxicos no Brasil: cultivando perigos. Ciência \& Saúde Coletiva, v.22, n.10, p.3333-3339, 2017. DOI: http://doi.org/10.1590/141812320172210.17112017
ALMEIDA, M. D.; CAVENDISH, T.; BUENO, P. C.; ERVILHA, I. C.; GREGÓRIO, L. S.; KANASHIRO, N. B. O.. A flexibilização da legislação brasileira de agrotóxicos e os riscos à saúde humana: Análise do Projeto de Lei no 3.200/2015. Cadernos de Saúde Pública, v.33, n.7, DOI: https://doi.org/10.1590/0102-311×00181016

ANDRADE, G. C. R.M.; MONTEIRO, S. H.; FRANCISCO, J. G.; FIGUEIREDO, L. A.; BOTELHO, R. G.; TORNISIELO, V. L.. Liquid chromatography-electrospray ionization tandem mass spectrometry and dynamic multiple reaction monitoring method for determining multiple pesticide residues in tomato. Food Chemistry, v.175, p.57-65, 2015. DOI: https://doi.org/10.1016/j.foodchem.2014.11.105

BELO, M. S. S. P.; PIGNATI, W.; DORES, E. F. G. C.; MOREIRA, J. C.; PERES, F.. Uso de agrotóxicos na produção de soja do Estado do Mato Grosso: um estudo preliminar de riscos ocupacionais e ambientais. Revista Brasileira de Saúde Ocupacional,v.37, n.125, p.78-88, 2012. DOI: https://doi.org/10.1590/\$0303-76572012000100011

BORGES, A. M.; BONOW, C. A.; SILVA, M. R. S.; ROCHA, L. P.; CEZAR-VAZ, M. R. Agricultura familiar e a conservação da saúde humana e ambiental. Revista brasileira de enfermagem, v.69, n.2, p.326-334, 2016. DOI: https://doi.org/10.1590/0034-7167.2016690216i

BRASIL. Decreto no 4.074. Regulamenta a Lei no 7.802, de 11 de julho de 1989, que dispõe sobre a pesquisa, a experimentação, a produção, a embalagem e rotulagem, o transporte, o armazenamento, a comercialização, a propaganda comercial, a utilização, a importação, a exportação, o destino final dos resíduos e embalagens, o registro, a classificação, o controle, a inspeção e a fiscalização de agrotóxicos, seus componentes e afins, e dá outras providências. Brasília: DOU, 2002.

BURALLI, R. J; RIBEIRO, H.; MAUAD, T.; AMATO-LOURENÇO, 
L. F.; SALGE, J. M.; DIAZ-QUIJANO, F.A.; LEÃO, R.S.; MARQUES, R. C.; SILVA, D. S.; GUIMARÃES, J. R. D.. Respiratory condition of family farmers exposed to pesticides in the state of Rio de Janeiro, Brazil. International Journal of Environmental Research and Public Health, v.15, n.6, 2018. DOI: https://doi.org/10.3390/ijerph15061203

CARNEIRO, R. P.; OLIVEIRA, F. A. S.; MADUREIRA, F. D.; SILVA, G.; SOUZA, W. R.; LOPES, R. P.. Development and method validation for determination of 128 pesticides in bananas by modified QuEChERS and UHPLC-MS/MS analysis. Food Control, v.33, n.2, p.413-423, 2013. DOI: https://doi.org/10.1016/j.foodcont.2013.02.027

CASALI, A. L.; SCHLOSSER, J. F.; GANDOLFO, M. A; UHRY, D.; RODRIGUES, F. A.. Nível de capacitação e informação dos operadores de máquinas para a aplicação de agrotóxicos Ciência Ruralncia Rural, v.45, n.3, p.425-431, 2015. DOI: https://doi.org/10.1590/0103-8478cr20121099

CESARINO, I.; MORAES, F. C.; LANZA, M. R.V.; MACHADO, S. A. S.. Electrochemical detection of carbamate pesticides in fruit and vegetables with a biosensor based on acetylcholinesterase immobilised on a composite of polyaniline-carbon nanotubes. Food Chemistry, v.135, n.3, p.873-879, 2012. DOI:

https://doi.org/10.1016/j.foodchem.2012.04.147

CEZAR-VAZ, M. R.; BONOW, C. A; MELLO, M. C. V. A.; SILVA, $M$. R. S.. Socio-environmental approach in nursing: focusing on rural labor and the use of pesticides. Revista brasileira de enfermagem, v.69, n.6, p.1179-1187, 2016. DOI: http://doi.org/10.1590/0034-7167-2016-0364

CORCINO, C. O.; TELES, R. B. A.; ALMEIDA, J. R. S. G.; LIRANI, L. S.; ARAÚJO, C. R. M.; GONSALVES, A. S.; MAIA, G. L. A.; Avaliação do efeito do uso de agrotóxicos sobre a saúde de trabalhadores rurais da fruticultura irrigada. Ciência \& Saúde Coletiva, v.24, n.8, p.3117-3128, 2019. DOI: https://doi.org/10.1590/1413-81232018248.14422017

DALBÓ, J.; FILGUEIRAS, L. A.; MENDES, A. N.. Effects of pesticides on rural workers: haematological parameters and symptomalogical reports. Ciência \& Saúde Coletiva, v.24, n. 7, p.2569-2582, 2019. DOI: https://doi.org/10.1590/1413$\underline{81232018247.19282017}$

DETÓFANO, D.; TEIXEIRA, M. L.; OLIVEIRA, L. F. S.; FUENTEFRIA, A. M.. Evaluation of toxicity risks in farmers exposed to pesticides in an agricultural community in Concórdia, Santa Catarina State, Brazil. Acta Scientiarum Health Sciences, v.35, n.1, p.111-118, 2013. DOI: https://doi.org/10.4025/actascihealthsci.v35i1.11227

DUTRA, R. M. S.; SOUZA, M. M. O.. Impactos negativos do uso de agrotóxicos à saúde humana. Revista Brasileira de Geografia Médica e da Saúde, v.13, n.24, p.127-140, 2017.

FARIA, N. M. X.; FASSA, A. G.; MEUCCI, R. D.. Association between pesticide exposure and suicide rates in Brazil. NeuroToxicology, v.45, p.355-362, 2014. DOI: https://doi.org/10.1016/j.neuro.2014.05.003

FONTENELLES, M. J.; SIMÕES, M. G.; FARIAS, S. H.; FONTENELLES, R. G. S.. Metodologia da Pesquisa Científica: diretrizes para elaboração de um protocolo de pesquisa, 2009.

GIL, A. C.. Como elaborar projetos de pesquisa. 6 ed. São Paulo: Atlas, 2017.
IBAMA. Instituto Brasileiro do Meio Ambiente e dos Recursos Naturais Renováveis. Relatórios de comercialização de agrotóxicos, 2020.

LONDRES, F.. Agrotóxicos no Brasil: um guia para ação em defesa da vida. 2011.

LOPES, C. V. A.; ALBUQUERQUE, G. S. C.. Agrotóxicos e seus impactos na saúde humana e ambiental: uma revisão sistemática. Saúde em Debate, v.42, n.117, p.518-534, 2018. DOI: http://dx.doi.org/10.1590/0103-1104201811714

MARTINI, L. F. D.; CALDAS, S. S.; BOLZAN, C. M.; BUNDT, A C.; PRIMEL, E. G.; AVILA, L. A.. Risco de contaminação das águas de superfície e subterrâneas por agrotóxicos recomendados para a cultura do arroz irrigado. Ciência Rural, v.42, n.10, p.1715-1721, 2012. DOI: http://dx.doi.org/10.1590/S0103-84782012001000001

MATOS, P. F.; PESSÔA, V. L. S.. A modernização da agricultura no Brasil e os novos usos do território. Geo UERJ, v.22, n.2, p.290-322, 2011. DOI: http://dx.doi.org/10.12957/geouerj.2011.2456

MOREIRA, J. C.; PERES, F.; SIMÕES, A. C.; PIGNATI, W. A.; DORES, E. C.; VIEIRA, S. N.; STRÜSSMANN, C.; MOTT, T.. Contaminação de águas superficiais e de chuva por agrotóxicos em uma região do estado do Mato Grosso. Ciência \& Saúde Coletiva, v.17, n.6, p.1557-1568, 2012. DOI: https://doi.org/10.1590/S1413-81232012000600019

NASRALA NETO, E.; LACAZ, F. A. C.; PIGNATI, W. A.. Vigilância em saúde e agronegócio: os impactos dos agrotóxicos na saúde e no ambiente. Perigo à vista!. Ciência \& Saúde Coletivas, v.19, n.12, p.4709-4718, 2014. DOI: https://doi.org/10.1590/1413-812320141912.03172013

OLIVEIRA, L. K.; PIGNATI, W.; PIGNATTI, M. G.; BESERRA, L.; LEÃO, L. H. C.. Processo sócio-sanitário-ambiental da poluição por agrotóxicos na bacia dos rios Juruena, Tapajós e Amazonas em Mato Grosso, Brasil. Saúde e Sociedade, v.27, n.2, p.573-587, 2018. DOI: https://doi.org/10.1590/s010412902018170904

PESSOA, V. M.; RIGOTTO, R. M.. Agronegócio: geração de desigualdades sociais, impactos no modo de vida e novas necessidades de saúde nos trabalhadores rurais. Revista Brasileira de Saúde Ocupacional - RBSO, v.37, n.125, p.6577, 2012. DOI: https://doi.org/10.1590/S030376572012000100010

PIGNATI, W. A.; LIMA, F. A. N. S.; LARA, S. S.; CORREA, M. L. M.; BARBOSA, J. R.; LEÃO, L. H. C.; PIGNATTI, M. G.. Distribuição espacial do uso de agrotóxicos no Brasil: uma ferramenta para a vigilância em saúde. Ciência \& Saúde Coletiva, v.22, n.10, p.3281-3293, 2017. DOI: https://doi.org/10.1590/1413-812320172210.17742017

PIGNATI, W.; OLIVEIRA, N. P.; SILVA, A. M. C.. Vigilância aos agrotóxicos: quantificação do uso e previsão de impactos na saúde-trabalho-ambiente para os municípios brasileiros. Ciência \& Saúde Coletiva, v.19, n.12, p.4669-4678, 2014.

PONTES, A. G. V.; GADELHA, D.; FREITAS, B. M. C.; RIGOTTO, R. M.; FERREIRA, M. J. M.. Os perímetros irrigados como estratégia geopolítica para o desenvolvimento do semiárido e suas implicações à saúde, ao trabalho e ao ambiente. Ciência \& Saúde Coletiva, v.18, n.11, p.3213-3222, 2013. 


\section{DOI: https://doi.org/10.1590/1413812320141912.12762014}

RIGOTTO, R. M.; SILVA, A. M. C.; FERREIRA, M. J. M.; ROSA, I. F.; AGUIAR, A. C. P.. Tendências de agravos crônicos à saúde associados a agrotóxicos em região de fruticultura no Ceará, Brasil. Revista Brasileira de Epidemiologia, v.16, n.3, p.76373, 2013. DOI:

https://doi.org/10.1590/S1415790X2013000300019

RIGOTTO, R. M.; VASCONCELOS, D. P. E.; ROCHA, M. M.. Pesticide use in Brazil and problems for public health. Cadernos de Saúde Pública, v.30, n.7, p.1360-1362, 2014. DOI: https://doi.org/10.1590/0102-311XPE020714

RUY, R.; REIS, T. E. D. S.. Risco de contaminação por agrotóxicos das águas subterrâneas em áreas cultivadas com cana-de-açúcar. Pesticidas: Revista de Ecotoxicologia e Meio Ambiente, v.22, p.77-84, 2012. DOI: http://dx.doi.org/10.5380/pes.v22i1.30800

SAMPAIO, R.; MANCINI, M.. Estudos de revisão sistemática: um guia para síntese criteriosa da evidência científica. Revista Brasileira de Fisioterapia, v.11, n.1, p.83-89, 2007. DOI: https://doi.org/10.1590/S1413-35552007000100013

SANTOS, C. L.; SILVA, H. S. V. P.; ANDRADE, G. V.; NUNES, G. S.. Avaliação da contaminação de corpos d'água adjacentes a áreas agrícolas da Ilha de São Luís (MA) por agrotóxicos. Pesticidas: Revista de Ecotoxicologia e Meio Ambiente, v. 22, n.1, p.85-95, 2013. DOI: http://dx.doi.org/10.5380/pes.v22i1.30801

SHINOHARA, N. K. S.. Insegurança alimentar no uso indiscriminado de agrotóxicos. Higiene Alimentar, v.31, n. 266, p.17-21, 2017.

SILVA, J. M.; NOVATO-SILVA, E.; FARIA, H. P.; PINHEIRO, T. M. M.. Agrotóxico e trabalho: uma combinação perigosa para a saúde do trabalhador rural. Ciência \& Saúde Coletiva, v.10, n.4, p.891-903, 2005. DOI: https://doi.org/10.1590/S1413-81232005000400013

SIQUEIRA, D. F.; MOURA, R. M.; CARNEIRO, G. E. L.; ARAÚJO, A. J.; CRUZ, S. L.. Análise da exposição de trabalhadores rurais a agrotóxicos. Revista Brasileira em Promoção da
Saúde, v.26, n.2, p.182-191, 2014. DOI: https://doi.org/10.5020/18061230.2013.p182

SIQUEIRA, S. L.; KRUSE, M. H. L.. Agrotóxicos e saúde humana: contribuição dos profissionais do campo da saúde. Revista da Escola de Enfermagem da USP, v .42, n.3, p.584590, 2008. DOI: https://doi.org/10.1590/\$008062342008000300024

SOARES, D. F.; FARIA, A. M.; ROSA, A. H.. Análise de risco de contaminação de águas subterrâneas por resíduos de agrotóxicos no município de Campo Novo do Parecis (MT), Brasil. Engenharia Sanitaria e Ambiental, v.22, n.2, p.277284, 2017. DOI: https://doi.org/10.1590/s141341522016139118

SOARES, W. L.; PORTO, M. F.. Atividade agrícola e externalidade ambiental: Uma análise a partir do uso de agrotóxicos no cerrado brasileiro. Ciência \& Saúde Coletiva, v.12, n.1, p.131-143, 2007. DOI: https://doi.org/10.1590/S1413-81232007000100016

SOUZA, G. S.; COSTA, L. C. A.; MACIEL, A. C.; REIS, F. D. V.; PAMPLONA, Y. A. P.. Presença de agrotóxicos na atmosfera e risco à saúde humana: Uma discussão para a vigilância em saúde ambiental. Ciência \& Saúde Coletiva, v.22, n.10, p.3269-3280, 2017. DOI: https://doi.org/10.1590/1413812320172210.18342017

SPADOTTO, C. A.; MATALLO, M. B.; MORAES, D. A. C.. Avaliação ambiental. Agroanalysis, v.30, n.5, p.41-42, 2010.

TOFOLO, C.; FUENTEFRIA, A. M.; FARIAS, F. M.; MACHADO, M. M.; OLIVEIRA, L. F. S.. Contributing factors for farm workers' exposure to pesticides in the west of the state of santa catarina, Brazil. Acta Scientiarum - Health Sciences, v. 36, n.2, p.153-159, 2014. DOI: http://doi.org/10.4025/actascihealthsci.v36i2.22383

VIERO, C. M.; CAMPONOGARA, S.; CEZAR-VAZ, M. R.; COSTA, V. Z.; BECK, C. L. C.. Risk society: the use of pesticides and implications for the health of rural workers. Escola Anna Nery - Revista de Enfermagem, v.20, n.1, p.99-105, 2016. DOI: https://doi.org/10.5935/1414-8145.20160014

A CBPC - Companhia Brasileira de Produção Científica (CNPJ: 11.221.422/0001-03) detém os direitos materiais desta publicação. Os direitos referem-se à publicação do trabalho em qualquer parte do mundo, incluindo os direitos às renovações, expansões e disseminações da contribuicão, bem como outros direitos subsidiários. Todos os trabalhos publicados eletronicamente poderão posteriormente ser publicados em coletâneas impressas sob coordenação da Sustenere Publishing, da Companhia Brasileira de Produção Científica e seus parceiros autorizados. Os (as) autores (as) preservam os direitos autorais, mas não têm permissão para a publicação da contribuição em outro meio, impresso ou digital, em português ou em tradução. 